\title{
Vocational-oriented teaching of foreign languages in technical institutes by using Internet
}

\author{
Anna Krivosphapkina*, Irina Savvina, Sardana Prokopieva \\ Institute of Foreign Philology and Regional Studies of M.K. Ammosov, North-Eastern Federal University, 58, Belinskogo Street \\ Yakutsk, 677000, Russia.
}

\begin{abstract}
The problems of vocational-oriented teaching and development of different skills of students of technical institutes are considered. The article gives review and analyses of new teaching technologies in teaching foreign languages for professional aims. Application of the Internet in vocational-oriented foreign language teaching enhances motivation of students to expand their own knowledge and attainments through various educational materials from electronic sources, which increases level of speaking and listening, as well as vocational-oriented skills of studying information obtained from the Internet. The model of the educational project "Internet for technical students in the foreign language classes" is considered in stages.
\end{abstract}

\section{Introduction}

Nowadays, foreign languages for professional aims are taught all over the world in a variety of ways. Since the fast development of the process of international consolidation and information exchange takes place, different specialists in different fields of industry, in supplement to traditional teaching, need vocationaloriented foreign language teaching, this allows efficient exchange of professional information.

It is necessary to point out that graduates of universities, including non-linguistic universities, today necessarily have to know a foreign language. However, graduates' level of foreign language proficiency is very in equable and sometimes leaves much to be desired. The long term problem of a unified foreign language program for students of technical institutes, that would take into account the necessary conditions for the level of training of graduates in a foreign language today, has become relevant. Today, such a program is recommended by the Scientific and Methodological Council on Foreign Languages. It is established on the provisions fixed in the modern documents on modernization of higher education. At the same time even with a unified program, it is constantly necessary to take into consideration the specifics of each institute or its departments, requirements of a consumer and the students themselves. As any other variety of education, education oriented on career uses many kinds of methods and accessions, and it depends on the available resources and the exact purpose of courses. Vocational-oriented learning can be separated into three main groups: problem-stated learning, autonomous learning, and learning with the support of technology of information and communication. It is worth noting that all these technologies are student-centered methods [1,120].

The use of the Internet should be regarded as one of the peculiarities of the technology of teaching foreign languages. The way of organization of Internet-stated studying is difficult process. All participants, students and instructors have to do much work during the whole process. Defining, identifying, and handling the processes of teamwork, organizing the interaction of different components are put together a given learning setup, and also methods of consolidation connecting links between these different components are included. Method of distance-learning [2] and approach of personality activity [3] in developing a model of foreign language teaching to technical institutes' students are necessary.

\section{Methods}

The most important role in professionally-oriented learning plays an instructor who can create a specific atmosphere of discussion and communication and in the classroom. Students can get sustained communication mastery and skills when they have the possibility to use all of them to speak with a native speaker. Unfortunately, sometimes it is impossible and in fact the instructor is the only foreign language speaker, so the students have some limit in time to talk to the instructor and each other during the lesson. Thus, to develop students' communication skills the instructor should think over and introduce suitable teaching processes and involve other resources in classroom work, and by all means including Internet resources to make student

\footnotetext{
Corresponding author: angava@mail.ru
} 
communicate outside of the classroom. Students have the opportunity to learn foreign languages more easily if they are enough stimulated and motivated and can use all their knowledge and acquired skills in some language atmosphere which would be appreciated and engaged in. Thus, from this point of view, vocational-oriented learning is an influential tool to realize this kind capacity. Students who study foreign languages accompanied by interesting and relevant materials have a good opportunity to use their skills in professional work and study. Students concentrate on material closely related to their major. Unfortunately, instructors use restricted materials in their classroom work. It is primarily textbooks with texts on students' specialty with a limited set of assignments to them. Consequently, most instructors often make their lesson plans using their own considered materials in professionally oriented teaching; specifically work out for particular objectives. Let us consider some of them. The ability to use collaborative development, accumulation, structuring of text and files, including multimedia programs, makes it inviting to work in the classroom, and for separate students' work. Web Quest is a website that students work with while completing a particular studying assignment. Web Quests are divided into two models: for short-term work to expand knowledge and its further incorporation. They are developed for long-term work to make students' skills complete and profound. Web Quests of the longterm is designed for one term or an academic year. The technology of web-quests helps to form and develop the following skills of students: the application of new technologies to solve vocational problems, including searching required information, the results of the learning process in the form of Power Point presentations, Movie Maker films and others; selfresponsibilities, mutual work and self-control; finding the solution of different problems the students can face during the working process, defining the rational options, increasing level of public speaking skills, being ready to help each other, the ability of taking root in conversation $[4,20]$. All these methods are necessary and desirable for self-study to make students to be ready for research work and activities, to stimulate their motivation to demonstrate their results and to gain experience in teamwork. The instructor should find and accommodate the way of using new technologies to make the group work more useful and successful with the help of Internet, multimedia and digital technologies and other applications.

\section{Results and Discussion}

Application of the Internet in vocational-oriented foreign language teaching enhances motivation of students expand their own knowledge and attainments through various educational materials from electronic sources, that increases level of speaking and listening, as well as vocational-oriented skills of studying information obtained from the Internet.

Application of the Internet in the classroom gives students realization that they can think, make comparison of different opinions and positions, debate, create their own opinion on the basis of knowledge of their own findings, experience, facts, laws of different science, and it provides the contentment for competence of critical thinking.

Students have the opportunity of getting such skills as: the ability of working with information and the ability of general academic knowledge.

Being engaged working with the Internet; students have free access to a great number of information and data from various scientific and information resources, students learn to find and obtain necessary information, process, store and convert it, which are the most important skill and competence for professional growth of students.

The ability of general academic knowledge successively facilitates students to develop and improve their academic skills appreciating, exploring some task, and finding the correct decision.

Getting the ability of working with obtained information and general academic knowledge during the process of acquiring intellectual competence of critical thinking students make a progress in developing communication and interaction skills, cognitive practice, creative and leading skills, independence of thinking, openness to something new and in mastering and expanding cultural, scientific, technical and economic knowledge, in solving different tasks and problems.

Students also acquire other skills except vocationaloriented ones:

- examining and searching works,

- creative teamwork on some project with mutual personal relations,

- a great variety of text works with authentic content,

- work on self-organizing, fast reaction,

- the ability of study something new

In technical institutes, development of text working student skills is given great attention, so it is worth mentioning that in vocational-oriented teaching of foreign languages students are interested in regional texts about culture of different countries and in vocational-oriented texts. Regional texts provide authentic and reliable data and information about some country events of the studied foreign language giving a possibility to master true living language. At the same time, it is particularly significant for those students whose future profession and activity will be related with activities with the association of technical and informatics fields, with mutual and collective work on some projects and inventions. In addition, regional texts have the capacity on the development and effect of intercultural and socio-cultural fields. This kind of texts include required expressions used in vocational-oriented situations of communication, necessary information about technical field that the student studies, professional technical terms that are used speaking with foreign colleagues.

Furthermore, materials of the texts should be thoroughly considered and selected by the instructor, so that the text meets the requirements of vocationaloriented and intercultural exchange situations to develop 
language and speaking skills, linguistic, intercultural, country-peculiar knowledge.

When students master all this knowledge as well as personal qualities including communication proficiency, frankness, tolerance and openness, future specialists are prepared to have direct dialogue both interpersonal and intercultural. At the same time, it is essential to reconsider the role of vocational-oriented skills and professional learning of technical specialists due to tenseness and rapidity of technological development all over the world. Studying foreign languages in technical institutes, students who use the Internet during classes and doing homework can solve vocational-oriented studying tasks by applying all necessary and useful information resources, participating in some telecommunication research projects, contests, conferences, exhibition works and forums.

Vocational-oriented texts taken from the vastness of the Internet provide an opportunity to learn natural language of native speakers, which is somehow differ from materials of the adapted textbooks, thereby it enables students to encourage and retain their cognitive motivation, and to improve their professional skills, the level of language skills and intercultural competence [5].

The main task of the instructor gives some kind of support and help to the students to adapt, and explain different kinds of exercises that make the students speak and understand the language structure.

Next important task of the instructor is to select the required Internet texts, which are a great number of them, and settle these texts according to their difficulty in grammatical and vocabulary content

Consequently, the instructor should be a professional and have great experience in pedagogical and methodical sphere of teaching, be aware of social and cultural life of the studied language country, understand the regional issue of the country, be familiar with the mentality of people living in the country. So, another important task of the instructor is to control and help the students to accommodate working with the Internet texts, and introduce adequate and suitable language and speaking tasks [6].

After all this work, students should be ready to make outcome in the form of the presentation of the speaking output. There are a variety of forms, which are possible to present this product, such as round table discussion, report, conference, talk show, interview and others. Preparation stage is the most important one for students, during it the students learn to work in one team, corporative and working skills are tested, thereby experiences of collaborative and cooperative activities are developed.

Telecommunication intercourse give students the opportunity to create a specific cognitive environment, the main features of which are: interactivity, when participants are in active teamwork in training with each other and networked information resources; medium saturation with various information, organization and ease of use of the information environment through special technological methods.

The Internet provides abundant opportunities for students to expand and increase reading and writing experience. Students have a great and real possibility to communicate through the Internet with the help of emails and various social nets and the use of different applications. Reading skills refer to semantic and emotional perception of the texts; the ability to look through the text quickly, to find the key moments of the text and to process necessary information. Writing skills belong to the ability to understand the text information, to make some individual and collective writing exercises, to create a project work in foreign languages.

Speaking and listening skills are also developed in the work with the Internet texts. To improve these skills it is required to produce activities as discussions, speech reports, teleconferences, talk show and interview; reviews of foreign newspapers, television and radio broadcasting, YouTube canals.

The instructor has another essential task in application of the Internet, to help students to use adopted knowledge and learn foreign languages on their own on the ground of practical use of the given study model, in which the principle of learning in different speech activity is vocational-oriented texts with authentic content.

Step-by-step classroom processes with different vocational-oriented texts from the Internet resources progresses and develops abilities and skills of independent student's work and strengthen learning interest. Mastering and acquaintance with information and technical fields of scientific learning as a means of getting reliable and useful information on scientific and technical achievements in native and foreign countries. Possession of working methods with the Internet material provides development and expanding of students' speaking and language skills, improves and increases the scope of communicative space during foreign language classes.

The most important aim of the given learning foreign language model is to raise the productivity of students' work with the Internet in professional way in technical institutes.

It is designed a learning model in the form of the model "Foreign language lessons with the application of the Internet in technical institutes. The aim of this learning project is to upgrade the educational content with the help of new information technologies in relation with the Internet.

This project works in conjunction with the research product, where students develop working and learning skills in the environment of Internet resources, simultaneously expanding educational tasks

In this project students are given a task, then they require to find necessary information from the Internet and present the final product.

Thereby, this project aims at the development of such students' competence as cognitive skills, when students are able to get, gather and put in order necessary information, think over it and broaden their knowledge. According to works of E.S. Polat, the project method focuses on integration of students' knowledge from various parts, in the process of solving some problem, 
students have an opportunity to use acquired knowledge in practice [7].

There are a number of coherent stages in the work and development of this learning project.

The first stage.

The purposes, tasks, and research methods are defined and working groups are formed.

At the beginning the groups are made up according to students' psychological reconcilability and language level. Research methods and strategy of searching the necessary information are considered. It is determined the main educational purpose and tasks that are expected to be solved during the working process and research activity on the project. After getting an assignment, students of the groups analyze it and take some advice from the instructor. General goals are carried out and each student of the group is given the role and the task.

The second stage.

Preparation part includes the work with the Internet; it consists of searching, collecting and sorting out the information for the content of the project.

During this stage students work on the Internet resource materials and study research and searching methods to find necessary information for the project on the given assignment; make a list of hypertext links topics to related graphics, texts and information. Students learn to operate and guide the networks applying different processes, recognize the basic searching means, principles of collecting and classifying information. Also, students learn the fundamentals of applying the Internet for self-studying, and it expands the knowledge and increases the motivation to learn foreign languages using the Internet.

Students' working groups arrange created language materials at first in the written form and then in oral form. It is introduced different new topical vocabulary during the research work. Participants of the project recognize and match the basic content for their presentation and get ready the results of their searching teamwork.

The third stage.

After analyzing and classifying collected information, the working groups make their own presentation of research work, which should reveal the given topic.

In this stage, project participants create home educational pages in free websites with the content of their research project which have links with their future professional work. These pages reflect like selfexpression of students group, and show the information working skills. The role of creativity is important in the group work, it is considered as the combination of obtained and processed information.

Students apply the Internet, navigate various elements using searching tools, detect the necessary information and thoroughly explore it. Saving information students print it. Students learn not only to apply the Internet in appropriate way, but, also to present it in the perceived form, to make an annotation, etc. At this stage, the reciprocal influence of the Internet and personality is especially pronounced, and the result is like a creative work.
Students consider advantages and disadvantages of the obtained materials making different suggestions and sharing their own opinion. During this stage, students develop writing, reading, speaking skills; work out grammatical and lexical skills

The fourth stage.

Students summarize the results of their project work; present all the received and processed information during the process of learning in this final stage. This stage is for cooperation work between students and the instructor, whereas the second and the third stages are for independent students work, they are given creativity freedom for the best solution of the given tasks, the instructor occasionally consult students and control their work. In the fourth stage the instructor is aware of the obtained information of each working group and answers the students' questions.

The results of the cooperation work are the development of various skills.

Speaking skills are worked out when creating an oral report based on the found information, students learn to express their own opinion and prove their point of view.

Reading skills are developed when reading authentic texts from the Internet, which include new vocabulary, and sorting out the basic concept of the given text.

The process of study with applying the Internet information resources has a number of psychological peculiarities. Students having free access to the achievements in the world of people activity of creativity have an opportunity to put on and define individual and distinctive content of the materials. A person being free from the influence of a great number of external factors of network in a psychological sense increases his or her horizons for realization and self-education.

Students' interaction in working with various materials has cognitive and educational tasks. The process of the project realization originates in mutual research and cognitive work between the students and the instructor. The instructor's activity is to be one of the information sources and organize independent work of the students' group. Position of the instructor consists in person-centered learning, providing consultant help, making a situation of student's self-affirmation and assisting students to realize, show and reveal themselves [8].

\section{Conclusion}

The combination of traditional methods of teaching and new teaching technologies in relation with the application of virtual world for supporting motivation of the students makes the professional learning more productive. Critical comprehension of the explored material by students facilitates to the establishing and fixing of different skills and capabilities, constitutes linguistic, cultural, professional and communication competency.

Therefore, vocational-oriented teaching of foreign languages to students of technical institutes with the support of the Internet is a system of a number of methodical and pedagogical conditions. This system 
keeps the combination of the goals content, measures, methodological and technological elements. Conditions of organization and pedagogical methods in using the Internet in educational process can change the learning techniques at institutes and form the students, information culture.

Organizational and pedagogical conditions for the use of the Internet can transform the learning process at the university and contribute to the formation of students' information culture. The application of the Internet increases motivation to study, expands the language proficiency level, contributes to the activation of research work in the students' environment, and encourages the students to be part of society participating in personal interaction.

\section{References}

1. Teaching ESP: Best Practices/ IBM PC CDROM: Published by "Repetitor Multi Media" for the English Language Office of the US Embassy (2012)

2. A.A. Andreev, Introduction to Interneteducation (2003)

3. I.S. Yakimanskaya, Personally-oriented approach: concept and technology (1996)

4. H. Basturkmen, Ideas and options in English for specific purposes. Routledge (2006)

5. S.V. Panyukova, Information and communication technologies in personally oriented teaching (1998)

6. E.S. Polat, Internet in lessons of foreign languages Foreign languages in school, 2, 14-19, (2001)

7. E.S. Polat, Method of projects in foreignlanguage lessons Foreign languages in school, 3, 3-9, (2000)

8. S.V. Titova Internet treasures for foreignlanguage teachers (Moscow University Press, 4, 202209, 2001) 